\title{
Distribution of prostaglandins in gastric and duodenal mucosa of healthy subjects and duodenal ulcer patients: effects of aspirin and paracetamol
}

\author{
S J KONTUREK,* W OBTULOWICZ, E SITO, J OLEKSY, S WILKON, AND \\ A KIEC-DEMBINSKA \\ From the Institute of Physiology and Pharmacology, Medical Academy and District Hospital, \\ Krakow, Poland
}

SUMMARY The distribution of mucosal $\mathrm{PGE}_{2}$-like activity was determined by bioassay technique in the body and antrum of the stomach and in the duodenum of healthy subjects and duodenal ulcer patients before and after administration of aspirin, paracetamol, or histamine. In healthy subjects, the oxyntic, antral and duodenal mucosa was found to be capable of generating large amounts of $\mathrm{PGE}_{2}$, which were not significantly different from those found in duodenal ulcer patients. No correlation was found between the generation of $\mathrm{PGE}_{2}$ and gastric acid secretory status or serum gastrin level. Aspirin - and to a much lesser extent, paracetamol-caused a dramatic reduction in the ability of the gastric mucosa to biosynthesise $\mathrm{PGE}_{2}$ and this was accompanied by marked side-effects and injury to the gastric mucosa. Administration of histamine caused small but significant reduction in the biosynthesis of $\mathrm{PGE}_{2}$ but it was accompanied by marked mucosal damage. This study indicates that the gastric and duodenal mucosa is capable of generating $P_{G E}$-like activity which may be involved in the mechanism that protects the mucosa against the damage caused by aspirin.

Human gastric mucosa has been shown to release prostaglandins under basal conditions and in response to secretory stimulation..$^{1-3}$ It has been postulated that prostaglandins may play a role in the control of gastric secretion ${ }^{4}$ and in the protection of gastric mucosa against physical or chemical injury. ${ }^{5}$ It has been suggested that the deficiency of mucosal prostaglandins is an important aetiological factor in peptic ulcer disease ${ }^{6} 7$ but no information is available regarding the generation and distribution of prostaglandins in human gastric mucosa.

This study was undertaken to determine the distribution of prostaglandins in gastric and duodenal mucosa of healthy subjects and duodenal ulcer patients and to examine the effects of nonsteroidal anti-inflammatory compounds and histamine administration on the generation of mucosal prostaglandins.

*Address for correspondence: Professor Dr S J Konturek, Institute of Physiology, 16 Grzegorzecka St, 31-531 Krakow, Poland.

Received for publication 18 November 1980

\section{Methods}

SUBJECTS

The study population was made up of 27 healthy volunteers with no previous history of gastrointestinal disease, bleeding disorders, or drug intolerance and 25 patients with active duodenal ulcer confirmed by endoscopy. Their average age was 28 years (range 20-34 years). They were not taking $\mathrm{H}_{2}$ blockers or anticholinergic drugs and had discontinued antacids for at least 24 hours before the examination. The study was approved by the Human Research Review Committee and informed consent was obtained from all participants after the nature of study has been fully explained.

The examination started in early morning after a 12 hour fast, and a venous blood sample was taken from all subjects for serum gastrin and salicylate determination. Then intravenous diazepam was given as premedication and gastro-duodenal endoscopy was performed with the Olympus GIF-D (Japan) endoscope. Four or five biopsy samples were obtained from the stomach body and antrum and the 
duodenal bulb. The mucosal samples were immediately plunged in ice-cold $0.05 \mathrm{M}$ Tris buffer, pH 9.0, and used immediately for the bioassay of prostaglandins as described below.

\section{MEDICATION}

The effects of aspirin and paracetamol on gastric mucosa and the mucosal generation of prostaglandins were examined in duodenal ulcer patients and healthy volunteers divided into two groups, each containing six to eight subjects. Aspirin, paracetamol, or placebo was given orally in tablets. Each tablet contained $0.5 \mathrm{~g}$ aspirin or paracetamol, which was administered in a total dose of $2.5 \mathrm{~g}$ divided into five doses of $0.5 \mathrm{~g}$ each: one given before breakfast, after lunch, after supper, at bedtime the day before examination, and in the early morning of the day of examination. In control tests, placebo tablets were administered in the same way as aspirin or paracetamol-that is, five times the day before and once on the day of examination. The study was fully randomised. Medications used in the study were purchased from standard commercial sources, while placebo was obtained from the Upjohn Co.

In addition, one group of the healthy volunteers was used for the study with histamine. The infusion of histamine was performed for 90 minutes in subjects fasted for 12 hours and gastric juice was aspirated throughout the infusion using a standard nasogastric tube. Histamine acid phosphate was given intravenously at a rate of $40 \mu \mathrm{g} / \mathrm{kg} / \mathrm{h}$ after blocking $\mathrm{H}_{1}$-effects with $50 \mathrm{mg}$ mepyramine maleate intramuscularly. Immediately after the infusion of histamine, the nasogastric tube was removed and gastroduodenoscopy was performed.

Duodenal ulcer subjects and volunteers involved in the study were instructed to avoid alcohol, all medications, and highly spiced food. They were requested to record all side-effects, but, for the purpose of this study, the target symptoms described were nausea, vomiting, epigastric pain or burning, and epigastric cramps. The overall subjective symptoms were characterised as minimal, moderate, or severe. About 10 days before the first dose and about five hours after the last dose of medication with aspirin, paracetamol, or placebo the gastroduodenal endoscopy was carried out and the gastric mucosa was observed and graded by the principal investigator, as described by Lanza et al. ${ }^{8}$ (Table). In all cases, a 0 grade was required at the initial endoscopy in order for the subject to continue in the study. In all cases four to five biopsy samples were obtained from the body and antrum of the stomach and from the duodenum and immediately plunged in

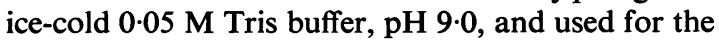
bioassay of prostaglandins.

\section{Table Grading of gastric mucosa}

\begin{tabular}{|c|c|}
\hline Grade & Description \\
\hline $\begin{array}{l}0 \\
1+ \\
2+\end{array}$ & $\begin{array}{l}\text { No evidence of submucosal haemorrhages } \\
\text { One submucosal haemorrhage } \\
\text { 1. More than one submucosal haemorrhage but not } \\
\text { numerous or widespread, or } \\
\text { 2. Oedema with two or more submucosal haemorrhages }\end{array}$ \\
\hline $\begin{array}{l}3+ \\
4+\end{array}$ & $\begin{array}{l}\text { Numerous areas of submucosal haemorrhages } \\
\text { Large area of submucosal haehorrhage with active } \\
\text { bleeding or widespread involvement in the stomach }\end{array}$ \\
\hline
\end{tabular}

Superficial ulcers were rated as haemorrhages. Invasive ulcers of any size were rated $4+$.

\section{GENERATION AND BIOASSAY OF MUCOSAL} PROSTAGLANDINS

Mucosal samples, which collectively weighed approximately $30-50 \mathrm{mg}$, were washed from blood and debris by shaking during five seconds with $1 \mathrm{ml}$ icecold Tris buffer and then centrifuging at $9000 \mathrm{~g}$ for 10 seconds. After the supernatant had been removed, a new volume of Tris buffer was added to residual tissue in the proportion of $0.5 \mathrm{ml} / 150 \mathrm{mg}$ of tissue weight. This sample was then shaken for 60 seconds at room temperature using a steady speed of a vortex stirrer and centrifuged at $9000 \mathrm{~g}$ for 15 seconds as described by Whittle. ${ }^{9}$ Supernatant was used for $\mathrm{PGI}_{2}$-assay immediately after centrifugation and then again after 30 minutes of storage at room temperature to destroy $\mathrm{PGI}_{2}$ for $\mathrm{PGE}_{2}$-assay.

The concentration of $\mathrm{PGI}_{2}$ in the supernatant was determined using its anti-aggregatory properties. ${ }^{10}$ Rabbit blood was withdrawn by heart puncture to $3.8 \%$ solution of sodium citrate $9: 1 \mathrm{v} / \mathrm{v}$. Platelet rich plasma (PRP) was prepared by centrifugation of citrated blood at $200 \mathrm{~g}$ for 10 minutes at room temperature. Platelet rich plasma was aggregated at $37^{\circ} \mathrm{C}$ in a Born aggregometer with threshold proaggregatory concentrations of adenosine diphosphate $(2-5 \mu \mathrm{M})$. The anti-aggregatory potency of standard $\mathrm{PGI}_{2}$ was measured by addition of $\mathrm{PGI}_{2}$ at concentrations of $0.4-10 \mathrm{ng} / \mathrm{ml}$ one minute before adenosine diphosphate was added. The percentage of inhibition of the adenosine diphosphate-induced aggregations was plotted against the effective concentrations of $\mathrm{PGI}_{2}$ to obtain a standard curve. To measure the amount of $\mathrm{PGI}_{2}$ generated by mucosa, 5-50 $\mu$ l of the supernatant from incubation samples were added to platelet rich plasma one minute before the addition of ADP. The generation of a $\mathrm{PGI}_{2}$-like activity in tested samples was calculated by comparing their anti-aggregatory potency with that of synthetic $\mathrm{PGI}_{2}$. Results are expressed in nanograms of the generated $\mathrm{PGI}_{2} / \mathrm{g}$ of tissue weight. The rat stomach strip and rat colon superfusion technique was used to determine the generation of $\mathrm{PGE}_{2}$ and $\mathrm{PGF}_{2 \alpha}$-like activity in the supernatant. ${ }^{11}$ 
Rat stomach strip and rat colon were superfused in cascade with pregassed $\left(95 \% \mathrm{O}_{2}\right.$ and $\left.5 \% \mathrm{CO}_{2}\right)$ Krebs solution containing such pharmacological antagonists as phenoxybenzamine $(2 \mu \mathrm{g} / \mathrm{ml})$, propranolol $(4 \mu \mathrm{g} / \mathrm{ml})$, atropine sulphate $(0.1 \mu \mathrm{g} / \mathrm{ml})$, methysergide $(0 \cdot 1 \mu \mathrm{g} / \mathrm{ml})$, diphenhydramine $(0 \cdot 1$ $\mu \mathrm{g} / \mathrm{ml})$, and indomethacin $(1 \mu \mathrm{g} / \mathrm{ml})$. The tone of rat stomach strip and rat colon was recorded with auxotonic levers (2-4 g initial load) using Harvard transducers type 386 connected to a Watanabe multirecorder. Calibration doses of $\mathrm{PGE}_{2}, \mathrm{PGF}_{2 \alpha}$, or $25-50 \mu l$ of supernatant were infused alternately over the assay organs. Results are expressed as nonograms of the generated $\mathrm{PGE}_{2}$ per gram of tissue weight.

MEASUREMENT OF MAXIMAL ACID SECRETION In each subject gastric secretory test was performed using pentagastrin in a dose $2 \mu \mathrm{g} / \mathrm{kg} / \mathrm{h}$ producing maximal acid secretion according to the method previously described. ${ }^{12}$ Peak-hour acid output was calculated from the sum of the two highest consecutive 15 minute outputs multiplied by 2 .

\section{SERUM GASTRIN AND SALICYLATE}

Venous blood obtained from the peripheral vein was allowed to clot and serum obtained by centrifugation was stored at $-20^{\circ} \mathrm{C}$ until assayed. Serum gastrin concentrations were measured by radioimmunoassay. ${ }^{13}$ All samples were tested in duplicate in the same assay. Antibody 4562 rabbit antiserum (kindly provided by Professor J F Rehfeld of Aarhus, Denmark) was used at a final dilution of 1:100 000. With this antibody all major molecular forms were measured on nearly equimolar basis, G-34 being about two-thirds as immunoreactive as G-17.

Serum salicylate concentrations were measured by the method of Saltzman. ${ }^{14}$

\section{STATISTICAL EVALUATION OF RESULTS}

Results are expressed as the mean \pm SEM. Student's $t$ test was used to determine the significance of difference between means, with differences giving a $P$ value of less than 0.05 being considered significant. ${ }^{15}$

\section{Results}

In all mucosal samples tested only the generation of $\mathrm{PGE}_{2}$-like activity was found, whereas $\mathrm{PGI}_{2}$ and $\mathrm{PGF}_{2 \alpha}$ were detected in negligible amounts and these results are not included into the presentation. The mean $\left( \pm\right.$ SEM) values of the generated PGE $_{2}$ like activity found in the oxyntic and antral portions of the stomach and in the duodenum are presented in Fig. 1. Both in normal subjects and in duodenal

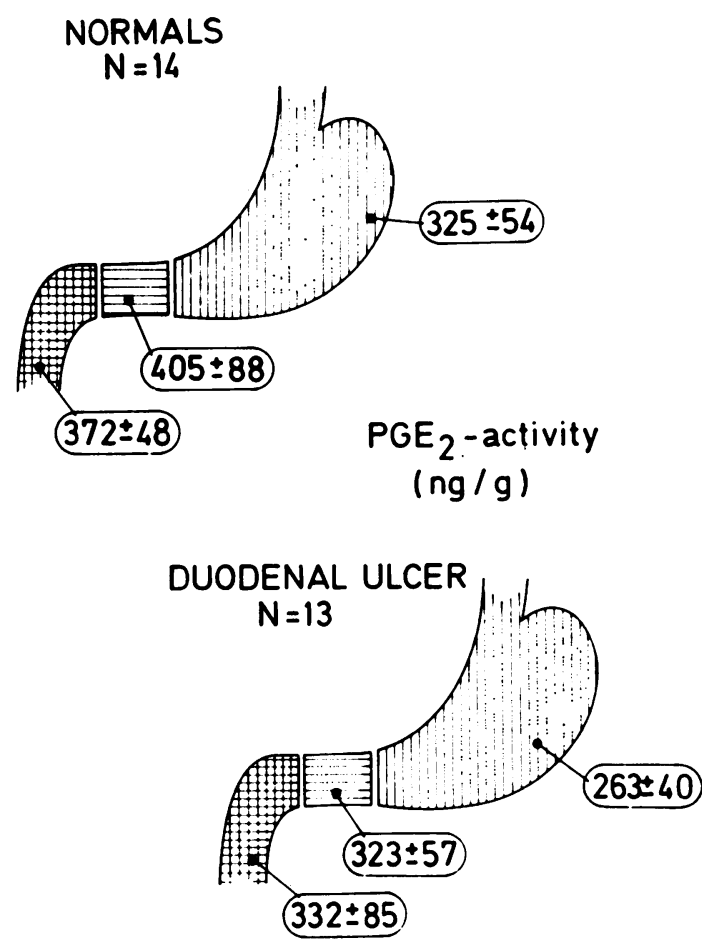

Fig. 1 Schematic presentation of the distribution of $P G E_{2}$-like activity in the oxyntic and antral mucosa of the stomach and in the duodenal mucosa of healthy subjects and duodenal ulcer patients.

ulcer patients, antral mucosa tended to generate larger amounts of $\mathrm{PGE}_{2}$ than oxyntic or duodenal mucosa but the difference was not significant. No significant difference in the generation of $\mathrm{PGE}_{2}$ was also found between the oxyntic and duodenal mucosa. Healthy volunteers tended to exhibit higher $\mathrm{PGE}_{2}$ biosynthesising capability in the oxyntic and antral mucosa than duodenal ulcer patients but, again, the difference in the generation of PGE $_{2}$ between these two groups of subjects was not statistically significant.

The mean pentagastrin-induced acid output in 14 normal subjects was $19.08 \pm 3.33 \mathrm{mmol} / \mathrm{h}$ and in 13 duodenal ulcer patients was $21.43 \pm 2.05 \mathrm{mmol} / \mathrm{h}$. The mean generation of $\mathrm{PGE}_{2}$ in oxyntic mucosa of healthy subjects was $325 \pm 54 \mathrm{ng} / \mathrm{g}$ and that of duodenal ulcer patients was $263 \pm 40 \mathrm{ng} / \mathrm{g}$. There was no correlation between maximal acid output and the generation of $\mathrm{PGE}_{2}$ either in healthy volunteers or in duodenal ulcer patients (Fig. 2).

Fasting serum gastrin in normal subjects averaged about $28.7 \pm 4.3 \mathrm{pM}$ and that in duodenal ulcer patients about $34 \cdot 6 \pm 5 \cdot 1 \mathrm{pM}$. There was no correlation between serum gastrin concentration and the 


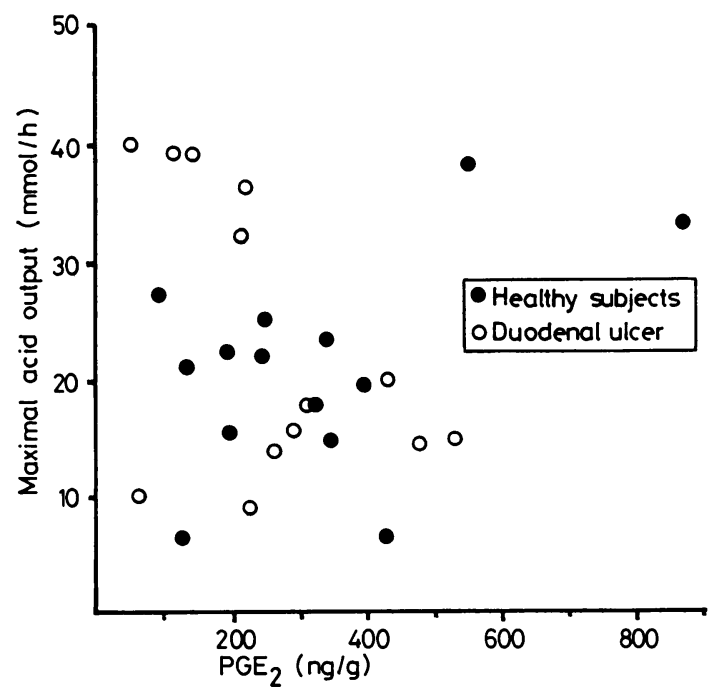

Fig. 2 Relationship between maximal acid outputs and the generation of $P G E_{2}$ in the oxyntic mucosa in healthy subjects and duodenal ulcer patients.

amounts of generated $\mathrm{PGE}_{2}$-like activity both in healthy subjects and duodenal ulcer patients.

In six duodenal ulcer patients and seven healthy subjects PGE $_{2}$-like activity was measured before (placebo) and after ingestion of $2.5 \mathrm{~g}$ aspirin. As shown in Fig. 3 the generation of $\mathrm{PGE}_{2}$ in gastric

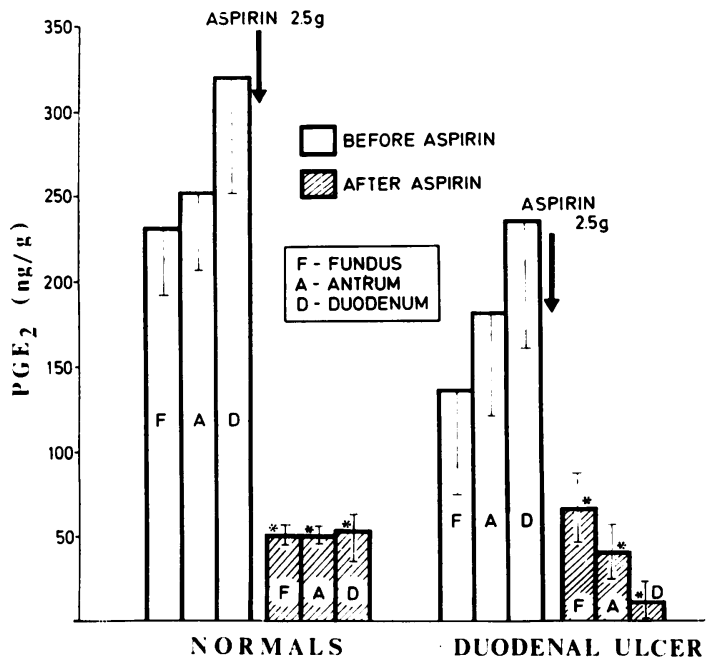

Fig. 3 The generation of $P G E_{2}$-like activity in gastric and duodenal mucosa of healthy subjects and duodenal ulcer patients before and after oral administration of aspirin. Mean $\pm S E M$ of seven healthy subjects and six duodenal ulcer patients. Asterisks indicate significant $(\mathrm{P}<0.05)$ decrease below the control value. and duodenal mucosa was dramatically and significantly reduced in all subjects tested. In healthy volunteers the fall in the generation of $\mathrm{PGE}_{2}$ was about $80 \%$ of the control level obtained with placebo. In duodenal ulcer patients, the $\mathrm{PGE}_{2}$-like activity almost completely disappeared from the duodenal mucosa and was reduced by over $60 \%$ in the oxyntic and antral mucosa.

Paracetamol given in the same dosage as aspirin $(2.5 \mathrm{~g})$ to six duodenal ulcer patients also significantly reduced the $\mathrm{PGE}_{2}$-like activity in the oxyntic and antral mucosa but the degree of this reduction was much less pronounced than after aspirin. No significant change in the $\mathrm{PGE}_{2}$ biosynthesising capability of the duodenal mucosa was observed.

Endoscopic findings and subjective symptoms were quite different in groups of subjects treated with aspirin and paracetamol. After aspirin ingestion four out of seven healthy subjects complained of nausea and moderate epigastric pain, whereas all six duodenal ulcer patients treated had moderate to severe symptoms of epigastric pain and abdominal

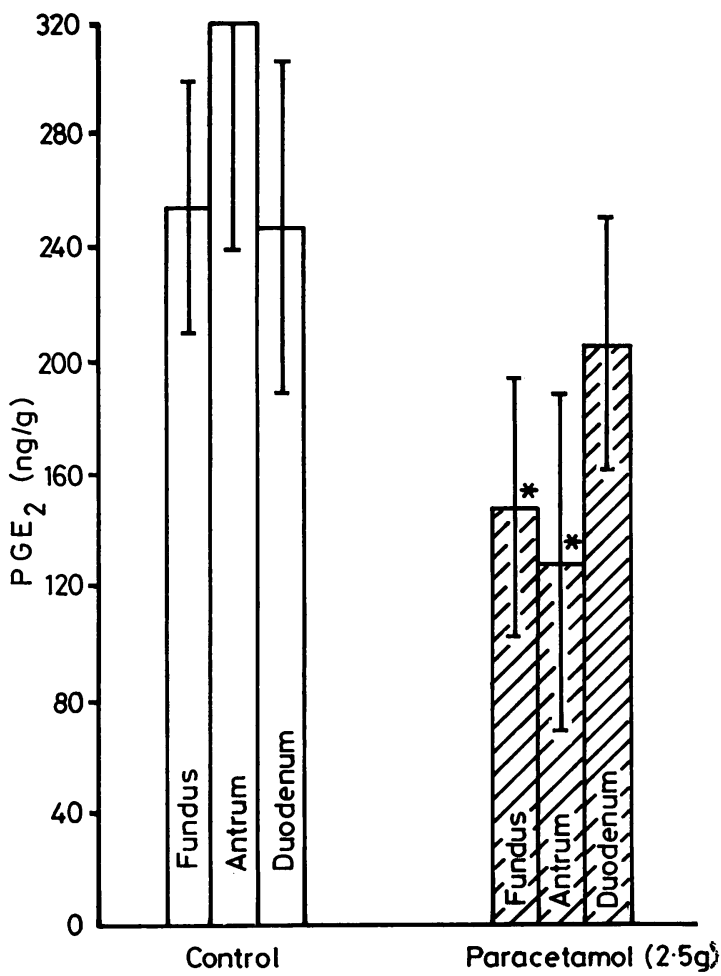

Fig. 4 The generation of $P G E_{2}$-like activity in gastric and duodenal mucosa before and after oral administration of paracetamol in duodenal ulcer patients. Mean $\pm S E M$ of six duodenal ulcer patients. Asterisks indicate significant $(\mathrm{P}<0.05)$ decrease below the control value. 
cramps. After paracetamol none of the healthy volunteers experienced side-effects and only two out of six duodenal ulcer patients complained of nausea and epigastric pain of mild degree (Fig. 4).

Endoscopic findings correlated quite well with the subjective symptoms. Ingestion of aspirin caused oedema, numerous submucosal haemorrhages and multiple erosions with active bleeding ( 3 or $4+$ endoscopic score) in most of the healthy subjects and in all duodenal ulcer patients examined. After paracetamol ingestion no sign of gastric mucosal injury was noted in three duodenal ulcer patients and in three others only mucosal oedema with single mucosal haemorrhages was observed $(2+$ endoscopic score). It should be noted that each of the subjects with 3 or $4+$ changes in the gastric mucosa reported moderate to severe gastrointestinal symptoms.

The infusion of histamine in a dose used to produce maximal secretory response caused a small but significant decrease in $\mathrm{PGE}_{2}$ biosynthesising capability of gastric and duodenal mucosa in five out of six healthy subjects (Fig. 5). The decrease in the generated $\mathrm{PGE}_{2}$-like activity ranged around $30 \%$ and was accompanied by marked mucosal damage $(3+)$ in all examined subjects. The major symptoms

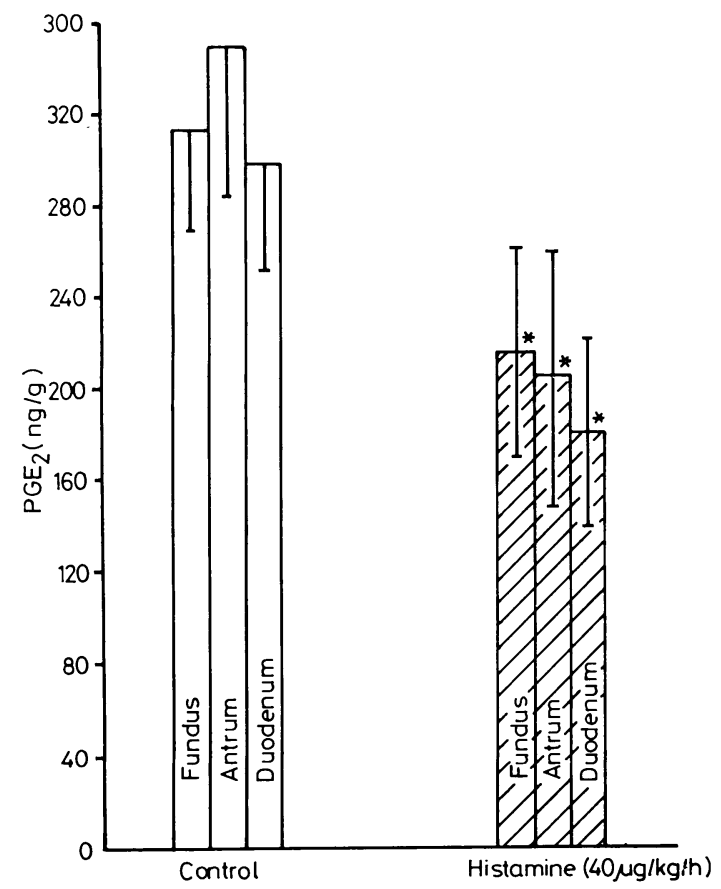

Fig. 5 The effect of histamine infusion on the generation of $P G E_{2}$-like activity of healthy subjects Mean \pm SEM of six observations in six subjects. Asterisks indicate significant $(\mathrm{P}<0.05)$ decrease below the control value. observed during histamine infusion included headache, flushing, and mild epigastric discomfort.

The serum salicylate levels that were obtained the morning of endoscopy after aspirin ingestion were comparable in healthy volunteers and in duodenal ulcer patients. Mean serum level was $125 \pm 29 \mu \mathrm{g} / \mathrm{ml}$ for healthy subjects and $134 \pm 37 \mu \mathrm{g} / \mathrm{ml}$ for duodenal ulcer patients.

\section{Discussion}

This study shows that human gastric and duodenal mucosa is capable of generating large amounts of bioassayable $\mathrm{PGE}_{2}$-like activity and negligible amounts of $\mathrm{PGI}_{2}$ or $\mathrm{PGF}_{2 \alpha}$. The gastric mucosa of duodenal ulcer patients tends to generate smaller amounts of $\mathrm{PGE}_{2}$ than that of healthy subjects but the difference is not statistically significant. As far as we know, this is the first report of the mucosal distribution of prostaglandins in healthy men and in duodenal ulcer patients. Previous studies tried to determine the prostaglandin levels in plasma and in gastric juic: in duodenal ulcer patients. Hinsdale et al. ${ }^{6}$ found significantly reduced levels of prostaglandins in the plasma and gastric juice of the duodenal ulcer patients under basal conditions and suggested that the prostaglandin deficiency may play a role in the pathogenesis of peptic ulcer disease. On the other hand, Baker et $_{\text {al. }}{ }^{3}$, using a highly sensitive radioimmunoassay system to measure $\mathrm{PGE}_{2}$, reported that plasma PGE concentrations in duodena! ulcer patients were within the normal range and were not related to gastric secretory status, serum gastrin level, or a specific diagnosis in dyspeptic patients. The discrepancy between the results of plasma prostaglandin reported by various workers ${ }^{36}$ could be attributed, at least in part, to the difficulties in the radioimmunoassay of prostaglandins and their almost complete removal from the circulation after a single passage through the lungs. ${ }^{16}$

Because of the above problems we decided to use the quick extraction and immediate bioassay technique; in the past this helped in the discovery of the major products of biotransformation of arachidonate via the cyclooxygenase pathway. We found that $\mathrm{PGE}_{2}$ is the predominant form of prostaglandins in the human mucosa and that $\mathrm{PGF}_{2 \alpha}$ and $\mathrm{PGI}_{2}$ can be detected by the bioassay system in negligible amounts. This may not mean that the human mucosa is unable to generate these prostaglandins but that these compounds are synthesised in relatively smaller amounts, just below the threshold of detection by our bioassay technique. In addition, human gastric mucosa may generate other products of arachidonate metabolism, such as thromboxanes, which could mask the synthesis of $\mathrm{PGI}_{2} \cdot{ }^{17}$ 
Our results indicate that the generation of $\mathrm{PGE}_{2}$ by the oxyntic mucosa does not show a statistically significant difference between the duodenal ulcer patients and healthy subjects and that this generation is not correlated with the gastric acid secretory capacity or serum gastrin level. Thus, it is unlikely that the mucosal prostaglandins play an important role in the pathogenesis of ulcer disease as suggested by Hindale et al. ${ }^{6}$ or in the local feedback control of gastric secretion as proposed by Baker and his colleagues. $^{3}$

The major finding of this study is the demonstration that aspirin, the most widely used representive of the non-steroidal anti-inflammatory compounds, causes dramatic reduction in the capacity of the gastric and duodenal mucosa to biosynthesise prostaglandins and that it is closely correlated with the subjective symptoms and the marked gastric mucosal injury. The fact that aspirin inhibits the biosynthesis of prostaglandins in other tissues by irreversible inactivation of the prostaglandin synthetase system ${ }^{18} 19$ is well recognised, but our report demonstrates for the first time the deficiency of gastric mucosal prostaglandins attributable to aspirin treatment in man and its relationship to gastrointestinal side-effects and gastric mucosal lesions. Aspirin is known to be poorly tolerated by duodenal ulcer patients ${ }^{20}$ and our study suggests that this intolerance is caused by severe damage to the gastric mucosa probably attributable to the deficiency of the mucosal generation of prostaglandins. This is supported also by our observation that duodenal ulcer patients receiving paracetamol, another widely used analgesic and antypyretic salicylate-like agent, ${ }^{21}$ reported little or no intolerance and this was accompanied by only mild gastroscopic mucosal changes and small reduction in mucosal generation of $\mathrm{PGE}_{2}$. The study with both aspirin and paracetamol suggests that mucosal prostaglandins play an important role in the integrity of gastric mucosa and that the suppression of the generation of mucosal prostaglandins by nonsteroidal anti-inflammatory compounds makes the mucosa more vulnerable to chemical injury and results in visible damage.

Baker et $a .^{3}$ reported that the stimulated gastric acid output is significantly correlated with the output of $\mathrm{PGE}_{2}$ into gastric juice, suggesting that the mucosal prostaglandins may play a role in the local control of gastric acid secretion. To test this hypothesis, we designed experiments in which the mucosal generation of prostaglandins was measured immediately after the infusion of histamine in a dose producing maximal gastric acid secretion was discontinued. The results of this study show that after secretory stimulation by histamine the genera- tion of mucosal prostaglandins tends to decrease and, therefore, the mucosal changes in prostaglandins may not be paralleled by prostaglandin changes in the gastric juice. Thus we failed to confirm the notion that mucosal prostaglandins may be involved in the feedback control of gastric secretion. ${ }^{34}$ However, our study confirms ${ }^{22}$ that histamine administration may, cause marked endoscopic mucosal damage without marked changes in the mucosal generation of prostaglandins. Thus, it appears that damage to the mucosa does not necessarily involve a reduction in the generation of mucosal prostaglandins and may, therefore, not be mediated by the deficiency of mucosal prostaglandins.

\section{References}

${ }^{1}$ Benett A, Stamford IF, Unger WG. Prostaglandin $\mathrm{E}_{2}$ and gastric acid secretion in man. $J$ Physiol 1973; 229: 349-60.

${ }^{2}$ Cheung LY, Jubiz W, Moore JG. Gastric prostaglandin $E_{2}$ output during basal and stimulated acid secretion in normal subjects and patients with duodenal ulcer. $J$ Surg Res 1976; 20: 369-72.

${ }^{3}$ Baker R, Jaffe BM, Venables CW. Endogenous prostaglandins in peptic ulcer disease. Gut 1979; 20: 394-9.

${ }^{4}$ Horton EW. Hypotheses on physiological roles of prostaglandins. Physiol Rev 1969; 49: 122-61.

${ }^{5}$ Robert A. Cytoprotection by prostaglandins. Gastroenterology 1979; 77: 761-7.

${ }^{6}$ Hinsdale JG, Engel JJ, Wilson DE. Prostaglandin $\mathrm{E}_{2}$ in peptic ulcer disease. Prostaglandins 1974; 6: 459-500. ${ }^{7}$ Baker R, Jaffe BM, Reed JD, Shaw B, Venables CW. Are prostaglandins deficient in peptic ulceration? Gut 1977; 18: 950-1.

${ }^{8}$ Lanza FL, Rayer GL, Nelson RS, Chen TT, Seckman CE, Rack MF. The effects of ibuprofen, indomethacin, aspirin, naproxen and placebo on the gastric mucosa of normal volunteers. Digest Dis Sci 1979; 24: 823-8.

${ }^{9}$ Whittle BJR. Potential endogenous inhibitor of prostaglandin synthetase in plasma failure to inhibit cyclooxygenase in platelets and the gastric mucosa. $J$ Pharm Pharmacol 1978; 30: 467-8.

${ }^{10}$ Gryglewski RJ, Bunting S, Moncada S, Flower RJ, Vane JR. Arterial walls are protected against deposition of platelet thrombi by a substance (prostaglandin $\mathrm{X}$ ) which prevents platelet aggregation. Prostaglandins 1976; 12: 685-9.

${ }^{11}$ Vane JR. The use of isolated organs for detecting active substances in the circulating blood. Br J Pharmacol Chemother 1964; 23: 360-73.

${ }^{12}$ Konturek SJ, Lankosz J. Pentapeptide infusion test. Scand J Gastroenterol 1967; 2: 112-7.

${ }^{13}$ Yalow RS, Berson SA. Radioimmunoassay of gastrin. Gastroenterology 1970; 58: 1-14.

${ }^{14}$ Saltzman A. Fluorophotometric method for the estimation of salicylate in blood. $J$ Biol Chem 1948: 174: 399-404.

${ }^{15}$ Siegel S. Nonparametric Statistics for the Behavioral Sciences. New York: McGraw-Hill, 1956 
${ }^{16}$ Piper PJ, Vane JR, Wyllie JH. Inactivation of prostaglandins by the lungs. Nature 1970; 225: 600-4.

${ }^{17}$ LeDuc LE, Needleman P. Regional localization of prostacyclin and thromboxane synthesis in dog stomach and intestinal tract. J Pharmacol Exp Ther 1979; 211: 181-8.

${ }^{18}$ Vane JR. Inhibition of prostaglandin synthesis as a mechanism of action for aspirin-like drugs. Nature $1971 ; 231$ : 232-5.

${ }^{19}$ Smith JB, Willis AL. Aspirin selectively inhibits prostaglandin production in human platelets. Nature 1971; 231: 235-7.
${ }^{20}$ Cooke AR. Drug damage of the gastroduodenum. In: Sleisenger MH, Fordtran JS, eds. Gastrointestinal disease. Philadelphia: Saunders, 1978: 807-26.

${ }^{21}$ Woodbury DM, Fingl E. Analgesic-antypyretics antiinflammatory agents, and drugs employed in the therapy of gout. In: Goodman LS, Gilman A, eds. The pharmacological basis of therapeutics. New York: MacMillan, 1975: 325-50.

${ }^{22}$ Siegel H, Harbilas E, Katz D, Glass GBJ. Gastric erosions and mucosal hemorrhage during the augmented histamine test. Gastroenterology 1967; 52: 1120. 